\title{
A study of the eye care provided by an accident and emergency department
}

\author{
M. J. CLANCY \& M. HULBERT
}

Departments of Accident \& Emergency Medicine and Ophthalmology St. James' University Hospital, Beckett Street, Leeds

\section{SUMMARY}

The eye care provided by an Accident and Emergency (A\&E) Department was prospectively studied over a 2 -month period. Six out of a total of 506 patients were deemed to have been treated unsatisfactorily by the A\&E Department. None of these patients suffered serious sequelae.

Approximately one in three of those patients seen solely by A\&E staff failed to have their visual acuity recorded.

\section{INTRODUCTION}

Patients with acute eye problems are said to seek help from their local hospital in preference to their General Practitioners (Vernon, 1983) and having presented to their A\&E Department are often examined by relatively inexperienced doctors who face eye problems with some anxiety (Anon, 1988). Hospitals manage these patients in different ways. Some arrange that all eye cases are seen by the Ophthalmology Department, some use the A\&E Department to see all such cases with the availability of an ophthalmic opinion, and others have a combination of these arrangements. At St James' University Hospital, Leeds, patients with acute eye problems are seen in the Ophthalmology Department if a clinic is in progress (totalling 6 half days per week) and by A\&E staff at all other times. Can A\&E Departments provide a satisfactory standard of eye care? In order to answer this question a prospective study was initiated.

\section{METHODS}

All patients with acute eye problems attended to initially by A\&E medical staff during September and October 1988 were studied. Their notes were analysed with

Correspondence: M. J. Clancy F. R. C. S. Registrar, Department of Accident and Emergency Medicine, St. James' University Hospital, Beckett Street, Leeds LS9 7TF, U.K. 
respect to diagnosis, treatment and speed of subsequent referral to the Ophthalmology Department. Patients going directly to the Ophthalmology Department without being seen by A\&E staff were not studied.

\section{RESULTS}

A total of 506 patients were seen by A\&E staff $(2.7 \%$ of all new attendances) and of these, 175 were referred. Of the 331 treated solely by the A\&E Department, patients with foreign bodies in their eyes formed the largest group, and those patients who from their history were thought to have a foreign body but in whom none could be found, formed the second largest group. Conjunctivitis, corneal abrasions and chemical splashes in the eye were the other large groups. See Figure 1.

Of these 331 patients 96 failed to have their visual acuity recorded in the affected eye, 8 patients had undiagnosed red eyes treated empirically with Chloramphenicol and 3 patients were prescribed steroid eye drops without ophthalmic advice. Of the 11 patients suffering from UV keratitis none were prescribed cycloplegics as has been recommended (Roper Hall, 1987) by some authorities. Only 11 patients returned and 2 of these could be considered to be mismanaged. The first was a patient whose foreign body had been missed and the other was a patient diagnosed as suffering from conjunctivitis who was subsequently found to have iritis. Both of these patients made satisfactory recoveries.

The distribution of diagnoses of the 175 patients referred to the Ophthalmology Department are shown in Figure 1. Again the commonest group were those patients with foreign bodies in their eyes. Speed of referral was judged to be satisfactory in all but four cases. There were two cases of undiagnosed painful red eye, one case of herpes keratitis, and one case of acute onset of multiple 'floaters'. In none of the cases referred was the treatment considered detrimental but the provisional A\&E diagnosis was revised by the Ophthalmologist in 27 cases.

\section{DISCUSSION}

We feel that the A\&E Department provided a satisfactory service in that none of the 331 patients treated by the A\&E Department alone suffered any significant eye damage and only 11 reattended. However the fact that nearly one third of the patients did not have their visual acuity recorded has serious implications in that reduced visual acuity is an important pointer to otherwise easily missed intraocular pathology, and for this reason failure to record visual acuity would not be defensible medico-legally. Patients with undiagnosed red eyes should be referred promptly and steroids should not be prescribed without ophthalmic advice (Rose \& Lavin, 1986). With the help of regular audit, feedback and education, the service can be improved. 


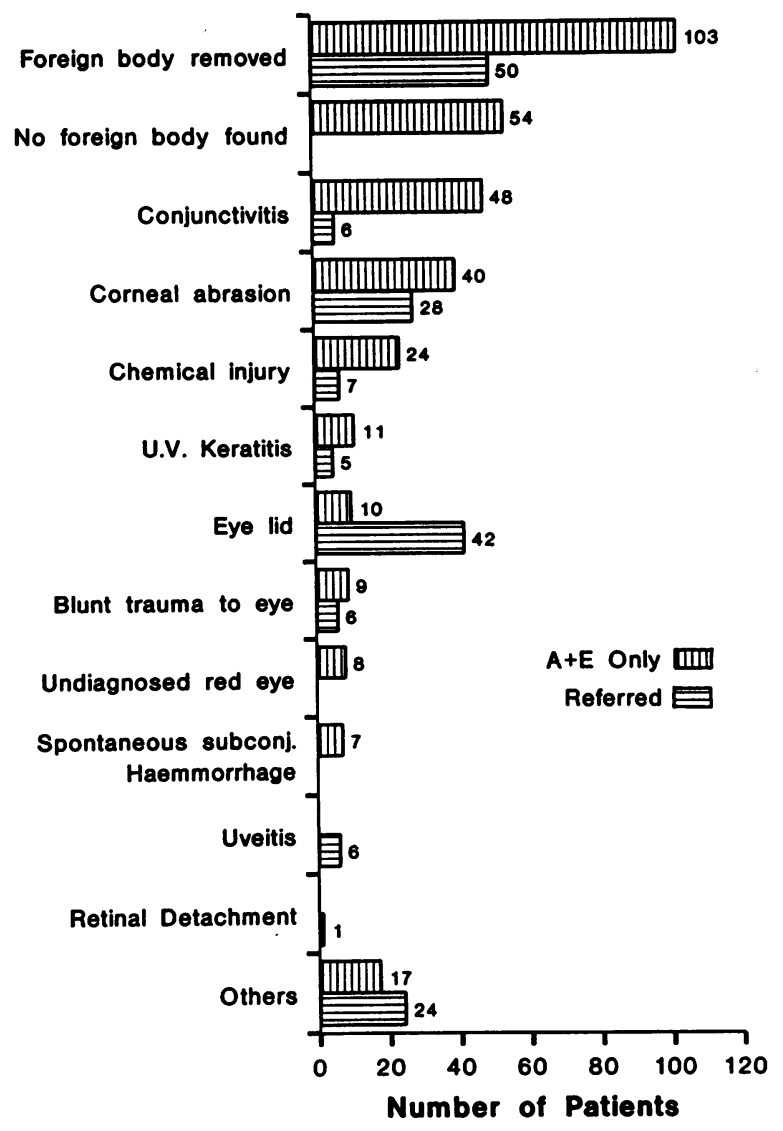

Fig. 1 Breakdown of eye problems.

\section{REFERENCES}

Anonymous (1988) A prospective survey of senior house officers as they begin work in an accident and emergency department. British Journal of Accident and Emergency Medicine 3 (3), 10-11.

Roper Hall M. J. (1987) Eye emergencies. Churchill Livingstone. London p. 76.

Rose G. E., Lavin M. J. (1986) British Medical Journal 293, 205.

Vernon S. A. (1983) Analysis of all new cases seen in a busy regional centre ophthalmic casualty $\frac{T}{0}$ department during a 24 week period. Journal of the Royal Society of Medicine 76, 279-82. 